\title{
(t)
}

\section{DETERMINAÇÕES DO RACISMO NO MERCADO DE TRABALHO: IMPLICAÇÕES NA “QUESTÃO SOCIAL" BRASILEIRA}

\author{
DETERMINATIONS OF RACISM IN THE JOB MARKET: \\ IMPLICATIONS IN BRAZILIAN "SOCIAL ISSUE"
}

\section{Tereza Cristina Santos Martins'}

\section{RESUMO}

Este artigo analisa o racismo no mercado de trabalho. Trata-se de uma pesquisa teórica que partiu dos processos sociais reais da sociedade brasileira para apreender as determinações do racismo. Ao determinar o "lugar" do(da) negro(a) na informalidade, no desemprego e nas relações de trabalho precárias, o racismo limitou/impediu os(as) trabalhadores(as) negros(as) de participarem da constituição política da "questão social".

Palavras-chave: Racismo. Questão social. Mercado de trabalho. Desemprego. Informalidade.

\section{ABSTRACT}

This article examines racism in the job market. It is a theoretical research that came from the real social processes of Brazilian society to grasp the determinations of racism. When determining the "place" of the black person in the informality, in the unemployment and in the precarious working relations, the racism limited/ prevented the black workers to participate of the political constitution of "social issue".

Keywords: Racism. Social issue. Job market. Unemployment. Informality. Submetido em 17/03/2014

1 Assistente Social, docente do Departamento de Serviço Social da Universidade Federal de Sergipe (UFS), doutora em Serviço Social pela Universidade Federal de Pernambuco (UFPE). E-mail: trzamartins@gmail.com. 


\section{temporalis}

\section{INTRODUÇÃO}

O Serviço Social tem na "questão social" a base da sua formação e exercício profissional. Ao longo dos anos, essa profissão vem desenvolvendo - do ponto de vista prático e teórico - uma ação na perspectiva da recusa à exploração e à dominação de classe. Tal recusa evidencia o seu compromisso com a classe trabalhadora. A despeito da ação verificada, chegamos ao século XXI sem grandes investimentos na reflexão teórica que dê conta das múltiplas determinações que fazem os(as) trabalhadores(as) negros(as) brasileiros(as) assumirem posição de destaque nas várias expressões da "questão social". Melhor dizendo, mesmo quando os indicadores sociais estão reiteradamente apontando para as condições de vida e de trabalho diferenciadas dessa parcela da classe trabalhadora, apenas uma parte minoritária do Serviço Social brasileiro empreende alguns esforços no sentido de colocar na pauta do dia o racismo brasileiro e suas consequências para $50,7 \%^{2}$ da população do país. Esses esforços, além de “pontuais [...], enfrentam uma série de 'senões' que inviabiliza uma reflexão efetiva, articulada e sistemática” (MARTINS, 2013, p. 15).

Evidentemente, essa sinalização é somente para observar que, como a "questão social" é central na formação e no exercício profissional, há uma urgência de o Serviço Social enfrentar o seu debate articulado aos indicadores sociais. Sem dúvida, esses indicadores revelam o quanto de exploração/opressão de raça/etnia/ gênero vem sendo efetivada contra os(as) trabalhadores(as) negros(as). Ora, se a estrutura da "questão social" é revelada pela lei geral da acumulação capitalista, não devemos esquecer que essa lei, apesar de "opera[r] independentemente de fronteiras políticas e culturais, seus resultantes societários trazem a marca da história que a concretiza" (NETTO, 2001, p. 48). Portanto, no Brasil, "as marcas da escravidão e do racismo não deixam de mediar as relações e os processos engendrados pelo seu 'capitalismo tardio"”'3 (MARTINS, 2013, p. 14) e, consequentemente,

\footnotetext{
2 Percentual de brasileiros(as) que, no Censo de 2010, se autodeclaram preto (15 milhões) e pardo (82 milhões) (IBGE, 2011).

3 Mandel (1982).
} 
interferem, agravam e aprofundam a conformação da "questão social".

A partir dessa compreensão, o presente artigo traz uma análise do racismo no mercado de trabalho brasileiro. Busca apreender as determinações que limitaram/impediram os(as) negros(as) de construir uma trajetória de organização e de luta, diante das suas condições de trabalho. Nesse sentido, aponta para o racismo como determinante da não inserção dos(das) negros(as) no mercado de trabalho formal. Tal determinação deixa essa parcela de trabalhadores(as) à margem da "cidadania regulada", impedindo-a de ter acesso à proteção social e aos processos organizativos a que se vincularam as respostas do Estado às expressões da "questão social".

\section{CENTRALIDADE DO TRABALHO E "QUESTÃO SOCIAL"}

A análise do debate do Serviço Social, particularmente aquele realizado por autores de tradição marxista, não deixa dúvida de que a "questão social", compreendida como "o conjunto das expressões das desigualdades sociais engendradas da sociedade capitalista madura" (IAMAMOTO, 2001, p. 27), aponta, inevitavelmente, para a relação capital/trabalho (a exploração) como sua determinação essencial. Aliás, essa relação assinala o trabalho como central na constituição da vida social, mas que não deve ser confundido com aquele trabalho "necessário [...] apenas e tão somente" para a reprodução do capital - o trabalho abstrato (LESSA, 2002, p. 31).

Essa assertiva remete à necessária consideração acerca do trabalho como categoria central e fundante do ser social. "O trabalho, portanto, enquanto formador de valores-de-uso, enquanto trabalho útil, é uma condição de existência do homem, independente de todas as formas de sociedade" (MARX, 1903, p. 9 apud LUKÁCS, 1979, p. 16). Nesse sentido,

é um processo de que participam o homem e a natureza, processo em que o ser humano, com sua própria ação impulsiona, regula e controla seu intercâmbio material com a natureza. Defronta-se com a natureza como uma de suas forças. Põe em movimento as forças naturais do seu corpo [...] a fim 


\section{temporalis}

de apropriar-se dos recursos da natureza externa e modificando-a, ao mesmo tempo modifica a sua própria natureza. Desenvolve as potencialidades nela adormecidas e submete ao seu domínio o jogo das forças naturais. Não se trata aqui das formas instintivas, animais, de trabalho. Pressupomos o trabalho sob forma exclusivamente humana (MARX, 2008, p. 211).

Nesses termos, o resultado do trabalho é um processo teleológico. É algo "que já estava presente de modo ideal. Ele não efetua apenas uma mudança de forma no elemento natural; ao mesmo tempo realiza, no elemento natural, sua própria finalidade" (MARX, apud LUKÁCS, 1979, p. 16). É diante dessa perspectiva que a ontologia marxiana do ser social recusa "a transposição simplista das leis naturais para a sociedade", mesmo porque o desenvolvimento das formas de objetividade do ser social "é um processo dialético, que começa com um salto, com o pôr teleológico do trabalho, não podendo ter nenhuma analogia na natureza" (LUKÁCS, 1979, p. 17).

Feita essa breve consideração acerca do "trabalho como categoria ontológico-fundante do ser social [...] e, portanto, como mediação ineliminável da existência humana" (LESSA, 2002, p. 34), cabe empreender algumas reflexões acerca do trabalho abstrato - tendo em vista a sua relação com a "questão social" e, obviamente, com o debate aqui proposto. Assim, "o trabalho abstrato é uma relação social na qual se produz mais-valia. Nesse sentido, todas as atividades humanas produtoras de mais-valia são trabalho no sentido de trabalho abstrato" (LESSA, 2002, p. 30, grifos do autor). Aqui reside o fato específico e particular que evidencia a relação do trabalho abstrato com a "determinação molecular da 'questão social"' (NETTO, 2001, p. 45) e, especificamente, com a expressão desemprego: a exploração via extração da mais-valia.

A extração de mais-valia como fonte de acumulação do capital influencia na redução da necessidade de força de trabaIho. Essa tendência é vista por Marx (2008, p. 748, grifos nossos) como um dos componentes da reprodução do capital, uma vez que 
a magnitude relativa do exército industrial de reserva cresce [...] com as potências da riqueza, mas quanto maior esse exército de reserva em relação ao exército ativo, tanto maior a massa da superpopulação consolidada, cuja miséria está na razão inversa do suplício de seu trabalho. E, ainda, quanto maior essa camada de lázaros da classe trabalhadora e o exército industrial de reserva, tanto maior, [...], o pauperismo.

Assim, compreendendo o desemprego como inerente à lógica do capital, cabe assinalar apenas que, na atualidade, ele se torna crônico pelo seu caráter estrutural. A sua novidade está no fato de que "as contradições ocorridas em qualquer uma de suas partes específicas complicam e agravam os problemas de outras partes e, consequentemente, de sua totalidade" (MÉSZÁROS, 2006, p. 32). Portanto, o processo de diminuir custos significa a mesma "necessidade de produzir desemprego" e vice-versa.

Os resultantes desse processo de acumulação capitalista, no Brasil, se evidenciam no desemprego, processado através do enxugamento da força de trabalho, que, em combinação com as mutações sociotécnicas no processo produtivo e com a organização do controle social do trabalho, tem ocasionado a flexibilização e a desregulamentação dos direitos sociais, especialmente, via terceirização. Por esse motivo, Mészáros (2006, p. 36) afirma que a precarização do trabalho, conduzida via o mito da flexibilidade, está geralmente ligada à autoritária legislação antitrabaIho, que estabelece "lei tendencial da equalização descendente da taxa de exploração diferencial”.

A despeito de afetarem toda a classe trabalhadora, o desemprego e/ou as formas precárias de trabalho não atingem igualmente brancos e negros. Ao contrário, o racismo que contribuiu para a construção de uma trajetória do negro no desemprego, na informalidade e na precarização das relações de trabalho, nesse contexto de crise e reestruturação produtiva, também vem determinando a sua inserção quantitativa nessas expressões da "questão social" - afinal, o racismo somente pode ser apreendido nas relações concretas da nossa sociedade. 


\section{temporalis}

\section{TRAJETÓRIA DO(DA) NEGRO(A) NO DESEMPREGO, NO TRABALHO PRECÁRIO E INFORMAL}

A transição capitalista no Brasil ${ }^{4}$ foi marcada pelo movimento de construção da ideia de inferioridade do(da) negro(a) e de sua incompatibilidade para assumir o trabalho assalariado. Portanto, no ideário da sociedade brasileira, o(a) negro(a) nada tinha a contribuir para o desenvolvimento do país. Aliás, segundo Martins (2012, p. 80), esse é um período em que o requisito racial torna-se imprescindível ao desenvolvimento brasileiro - razão pela qual a política de imigração europeia busca viabilizar força de trabalho compatível com o modelo de desenvolvimento desejado e o branqueamento da população. Não é por acaso que na cidade de São Paulo5 , até pelo menos 1920, 52\% dos trabalhadores na indústria "continuavam sendo estrangeiros, e, dentre os $48 \%$ restantes, a maior parte era filho de imigrantes, indicando a preferência que o industrial mantinha pela mão de obra de origem ou ascendência estrangeira" (KOWARICK, 1994, p. 93).

Esses dados são reveladores de como o racismo no mercado de trabalho acabou deixando os(as) trabalhadores(as) negros(as) e seus(suas) descendentes à margem dos setores mais dinâmicos da economia brasileira. Esse processo os(as) limitou a uma situação de desocupação e/ou de ocupação em atividades menos atrativas (HASENBALG, 2005, p. 189) e, consequentemente, com salários mais baixos. Esse quadro, em parte, explica os motivos pelos quais

[...] paralelamente ao início da industrialização [, quando] se consolida a legislação trabalhista/corporativista, os trabalhadores organizados e protegidos por estas leis e pelo salário mínimo eram relativamente poucos, ainda localizados em algumas capitais e em meio a uma imensa maioria de trabalhadores no campo e de marginalizados das cidades sem quaisquer direitos sociais (MATTOSO, 1995, p. 122, grifos nossos).

4 A transição está sendo considerada do período que vai de 1888 a 1930.

5 Essa cidade, caracterizada pelo dinamismo a partir de 1890, chega a $1907 \mathrm{com}$ $16 \%$ da produção industrial brasileira, crescendo para 31\% em 1919 e para $37 \%$ em 1929 (CANO, 1998). 
De fato, na década de 1940, quando se consolidam as relações de trabalho sob bases corporativistas, os negros e "mulatos ${ }^{6}$ " formavam $40 \%$ dos que se encontravam inseridos no setor primário da economia, compondo $46 \%$ dos empregados, $41 \%$ dos autônomos e 22\% dos empregadores. Em 1950, essa população é acrescida, contando com $42,5 \%$ dos que trabalhavam nesse setor, sendo $47 \%$ dos empregados, $43 \%$ dos autônomos e $22 \%$ dos empregadores (HASENBALG, 2005, p. 179-180).

Se a década de 1950 representou um marco importante na associação da economia brasileira com o capital internacional, a partir de 1964, verifica-se o seu aprofundamento. Nessa conjuntura, concretiza-se a "revolução burguesa"7, cujos traços oligárquicos, autárquicos e senhoriais da burguesia brasileira constituem a sua marca. Sem dúvida, o desenvolvimento operado a partir da primeira fase de "industrialização pesada" (1956-1964) possibilitou uma maior inserção dos(das) negros(as) no mercado de trabalho que, de $36 \%$ em 1950 , chega a $62 \%$ em 1980. Em 1980, essa população já se concentrava nas áreas urbanas (62\%), diferentemente da década de 1950 (36\%). Entretanto, a absorção significativa da força de trabalho negra na indústria de transformação dinâmica $(16,4 \%)$ e na indústria tradicional $(13,4 \%)$ era predominantemente nas ocupações manuais e de menor nível de rendimento (PORCARO, 1988, p. 178-192). A vinculação empregatícia dos(das) negros(as) estava associada às ocupações irregulares, com tendência a flutuações cíclicas e sazonais. Portanto, invariavelmente, com poucas chances de ser regulamentada por leis trabalhistas.

Os dados acima apontam para as relações de exploração/ opressão de raça/etnia, ou seja, relações que se expressam também na divisão sexual do trabalho. Tal divisão é aqui entendida nos termos de Kergoat (2003, p. 55), isto é, como "divisão do trabalho social decorrente das relações sociais de sexo", cujos

6 A utilização dessa classificação decorre somente do fato de que estou utilizando os dados secundários e, portanto, estou sendo fiel à análise do autor.

7 Fernandes (2006, p. 239) concebe a Revolução Burguesa como "um conjunto de transformações econômicas, tecnológicas, sociais, psicoculturais e políticas que se realizam quando o desenvolvimento capitalista atinge o clímax de sua evolução industrial". 


\section{temporalis}

princípios organizadores estão assentados na "separação (existem trabalhos de homens e trabalhos de mulheres) e [na] hierarquização (um trabalho de homem 'vale' mais do que um trabalho de mulher)". Essa divisão é perceptível na análise de Bairros (1991, p. 185). A autora verifica que as transformações operadas na estrutura produtiva da Bahia levam a uma expansão da participação das mulheres: de $44 \%$ de mulheres assalariadas, na década de 1950 , para $63 \%$ na década de 1980 . No entanto, não há alterações nas atividades atribuídas aos papéis historicamente definidos para as mulheres, tampouco para as mulheres negras. Esse fato mostra a afirmação dos espaços ocupacionais femininos, os quais revelam um continuum nas relações de poder e dominação patriarcal, nos termos de Saffioti (2004), e, ao mesmo tempo, uma reafirmação dos "lugares" historicamente destinados às negras.

De fato, Bairros (1991, p. 182-183) identifica que a predominância das mulheres no ramo de prestação de serviço se deve "à sua concentração nos serviços pessoais (cabeleireiros, manicures, estilistas, lavadeiras, passadeiras, confecção [...]) e nos serviços domiciliares". Nesse ramo, "o serviço doméstico remunerado é responsável por $67,8 \%$ da ocupação". Nesse caso, verifica-se a existência de uma "apartação" entre negras e brancas, ou seja, nos serviços domiciliares, as negras, particularmente as pretas, chegam a $86,4 \%$ das trabalhadoras ocupadas. Já nos serviços pessoais, as mulheres brancas estão mais presentes, chegando a $24,2 \%$, ao contrário das negras que chegam a $12 \%$. Tal fato revela o quanto as ocupações relacionadas aos serviços pessoais e ao comércio, segundo Bairros (1991, p. 183), "ainda são profundamente marcadas por fatores restritivos à ocupação de negros", principalmente porque elas exigem um maior contato com o público a quem o serviço se destina. Portanto, se se observa a exploração/opressão de gênero relacionada a todas as mulheres, não resta dúvida de que essa exploração/opressão se afirma duplamente no que tange às mulheres negras: pelas relações de gênero e étnico-raciais.

Entretanto, Bairros (1991, p. 192) observa que, "mais do que o sexo", a raça carrega determinações contundentes na definição de uma participação menor das trabalhadoras negras nas 
ocupações socialmente mais valorizadas e, evidentemente, com melhor remuneração.

O "lugar" dos(das) negros(as) na estrutura produtiva também se verifica no emprego público. Mesmo sendo aquele no qual há uma maior aproximação na representatividade entre negros(as) e brancos(as), apresenta-se como um divisor entre os empregos hierarquicamente mais elevados e mais bem remunerados e os empregos menos prestigiados e com um menor salário (ANDREWS, 1998, p. 199). Portanto, a materialização do racismo através das diferenças salariais, mesmo nos empregos "hierarquicamente mais elevados", mostra-se nos dados da Pesquisa Nacional por Amostra de Domicílio (PNAD) de 1976 e de 1982 e do Censo de 1980. Eles evidenciam uma crescente desigualdade salarial na mesma proporção que se eleva o nível de escolaridade dos(das) negros(as).

A análise do racismo, ao longo dos processos que conformaram a constituição e o desenvolvimento do mercado de trabalho brasileiro - no âmbito do "capitalismo retardatário" -, não deixa dúvida de que o racismo, ao se articular às determinações da sociabilidade do capital, traz em si determinações contundentes, com consequências incisivas na vida da classe trabalhadora negra. Portanto, revela que

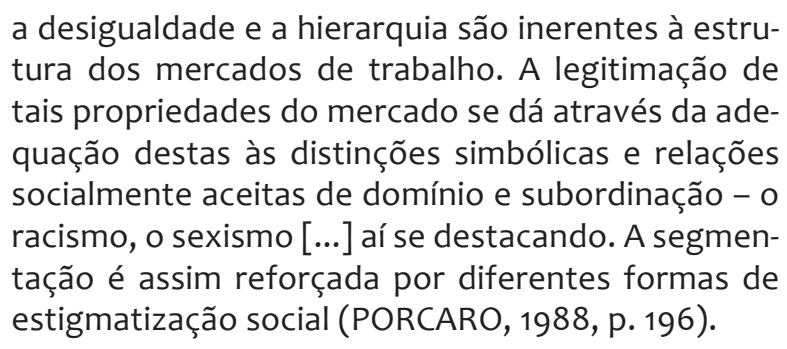

Nessa linha de argumentação, cabe enfatizar que o racismo brasileiro não pode ser entendido como mera discriminação inconsequente. Ele interfere objetivamente nas condições sociais dos(das) racialmente discriminados(as) e, também, dos(das) não discriminados(as) racialmente. Logo, as relações étnico-raciais devem ser apreendidas nos processos sociais reais do capitalismo brasileiro. Pela relevância assumida nos processos que envolvem as relações sociais na sociedade brasileira, o racismo deve ser 


\section{temporalis}

visto como reiterador das desigualdades nas condições materiais de vida e de trabalho dos(das) negros(as) brasileiros(as) (MARTINS, 2013, p. 12-13) e, portanto, determinação relevante no aprofundamento da "questão social".

Enquanto determinação reiteradora, o racismo reforça a exploração/opressão de raça/etnia. Não é por acaso que, "de maneira geral, os pretos e pardos apresentam baixo grau de formalização nas relações de trabalho em comparação aos brancos, se observarmos as taxas de contribuição previdenciária e carteira assinada" (BATISTA; GALVÃO, 1992, p. 85). Evidentemente, por se inserir nos ramos menos protegidos, a exemplo das atividades agrícolas, indústria da construção e prestação de serviços, o(a) negro(a) experimenta a informalidade em proporção bem maior que o(a) branco(a) e amarelo(a). Nesse sentido, Batista e Galvão (1992, p. 86) observam que $1 / 4$ da população ocupada, em 1987, se concentrava no setor primário, o menos protegido, daí porque "o grau de formalização se constitui em mais um elemento a confirmar a situação de desvantagem da mão de obra [negra] no mercado de trabalho", principalmente quando se considera o grau de flexibilidade estrutural e precariedade das ocupações no Brasil.

Cabe notar que embora a flexibilidade seja característica do mercado de trabalho brasileiro (BALTAR; PRONI, 1996, p. 112-113), ela não atinge igualmente os(as) trabalhadores(as). Ao contrário, os(as) trabalhadores(as) racialmente discriminados se concentram nos empregos de maior rotatividade da força de trabalho, de maior informalidade e de menor nível salarial. Essa assertiva é confirmada por Porcaro (1988, p. 189-192), quando localiza mais de $80 \%$ dos(das) negros(as) em apenas cinco setores de atividades com prevalência de trabalho secundário, ou seja, nos setores de trabalho instáveis e mal remunerados, marcados pela constante troca de emprego:

[...] no nordeste: setor primário 52,4\%; prestação de serviço, 10,9\%; comércio de mercadorias, 7,2\%; indústria tradicional, 7,0\%; e a construção civil, 6,6\%;. [...] em São Paulo [...] prestação de serviços $(20,1 \%)$ [...] com o crescimento da demanda por serviços pessoais, de confecção, de higiene pessoal etc., e domiciliares (15,5\%), no qual se destaca o serviço 
doméstico remunerado $(11,7 \%)[\ldots]$ [e] outros serviços de prestação de serviços (4,6\%) [...] A construção civil e a prestação de serviços [...] quase $40 \%$ das pessoas ocupadas no primeiro e $32,7 \%$ no segundo são negras, enquanto a média em São Paulo é de $24,4 \%$.

A continuidade e o aprofundamento dessas relações de exploração/opressão étnico-racial e de gênero são verificados a partir da década de 1990, quando os ajustes das políticas neoliberais são implementados. Nessa conjuntura, os(as) trabalhadores(as) negros(as) compõem as mais altas taxas de subemprego, de menor nível de rendimento e de não acesso à Previdência Social. Nesse sentido, se a crise do emprego no Brasil, a partir das décadas de 1980 e 1990, do século XX, se opera, a trajetória histórica dos(das) negros(as) nas ocupações não assalariadas e precárias tende a se aprofundar e se estender quantitativamente. No período de 1995 a 2006, por exemplo, na condição de assalariados com carteira assinada, 36,8\% eram brancos(as) e $28,5 \%$ eram pretos(as) e pardos(as). Enquanto os homens brancos chegavam a $33 \%$, as mulheres pretas e pardas totalizavam $22 \%$. No emprego assalariado sem carteira assinada, os homens pretos e pardos chegavam a $25,2 \%$ e os brancos a $17,2 \%$. Entre as mulheres, as pretas e pardas perfaziam um percentual ligeiramente superior (PAIXÃO; CARVANO, 2008, p. 97).

Assim, os indicadores levantados por Paixão e Carvano (2008, p. 97) dão conta de que o peso relativo do emprego sem a carteira assinada, na População Economicamente Ativa (PEA) ocupada/assalariada - tanto no setor privado quanto no público -, no período de 1995 a 2006, perfaz 25\% para a PEA branca. Dentro desse grupo étnico-racial, $27,3 \%$ eram para a PEA masculina e de $23,9 \%$ para a feminina. Quando se analisam os indicadores da PEA preta e parda assalariada, o peso relativo foi de $37,6 \%$ dos empregados sem carteira assinada. Na decomposição desse grupo étnico-racial por sexo, identifica-se que a PEA masculina chegou a $40,1 \%$, enquanto a feminina foi de $32,5 \%$. Portanto, a análise a partir do enfoque étnico-racial evidencia que os pretos e pardos (55,5\%) ocupam, em maior proporção, os trabalhos informais e sem carteira assinada. Já os(as) trabalhadores(as) brancos(as) se 


\section{temporalis}

inserem nos empregos privados com carteira assinada (57,1\%) e no serviço público $(57,8 \%)$. Esses indicadores não são casuais. Eles refletem a existência, ao mesmo tempo, do racismo impregnado na estrutura produtiva do capitalismo brasileiro e a exploração/ opressão que se opera através das relações de classe, étnico-raciais e de gênero.

Nessa mesma linha de preocupação, cabe destacar que o trabalho doméstico, por estar associado a um maior grau de informalidade e precarização, é mesmo assumido essencialmente pelos(as) negros(as). No período de 1995 a 2006, entre os(as) trabalhadores(as) pretos(as) e pardos(as), nessa ocupação, $75,8 \%$ estavam sem carteira assinada. Dentro desse grupo étnico-racial, 76,1\% eram mulheres e 63,6\% eram homens. Logo, esses(as) trabalhadores(as) não possuíam os seus direitos trabalhistas garantidos. Nessa ocupação, os brancos chegavam a $68,9 \%$. Desse percentual, $57,1 \%$ eram homens e $69,8 \%$ mulheres. No grupo de trabalhadores(as) domésticos(as) com carteira assinada, $53,8 \%$ eram pretos(as) e pardos(as), sendo que, do total de empregados sem carteira assinada, o peso dos homens pretos e pardos chegou a 3,3\% e o das mulheres a 58,2\% (PAIXÃO; CARVANO, 2008, p. 98).

Esse quadro de exploração/opressão de gênero e de raça/ etnia é reforçado por Bruschini e Lombardi (2003, p. 347) quando caracterizam a estrutura ocupacional feminina brasileira em dois segmentos diferentes, em relação a qualificação, prestígio e remuneração. Assim, apesar de verificarem uma redução da desigualdade salarial entre homens e mulheres, afirmam que "o mercado de trabalho não tem apenas uma segmentação de gênero, mas também de raça/cor" (BRUSCHINI; LOMBARDI, 2003, p. 355). Essa combinação sexo-raça repercute nas condições de trabalho das mulheres negras. Aliás, essa repercussão aponta para uma maior discriminação das trabalhadoras negras.

Portanto, as análises atéentão empreendidas evidenciamque a informalidade e a precariedade nas relações de trabalho caracterizam a trajetória do negro e, fundamentalmente, das mulheres negras brasileiras. Nesse sentido, Paixão e Carvano (2008, p. 98) reafirmam que no período de 1995 a 2006 a informalidade atingiu 
relativamente mais a população preta e parda. Ou seja, enquanto 53,3\% da PEA branca estava inserida em ocupações informais, 65\% da PEA preta e parda vivenciava essa situação. Ao verificarem os indicadores a partir do enfoque étnico-racial e de gênero, constataram que 51,1\% da PEA branca era masculina, enquanto 54,1\% era feminina. Da PEA preta e parda inserida na informalidade, 61,5\% eram homens e quase $75 \%$ mulheres.

Sem dúvida, essas condições de trabalho repercutem nas condições de vida de homens e mulheres negros(as). Refletem, principalmente, no empobrecimento feminino, sobretudo diante do crescente número de mulheres trabalhadoras que sustentam as suas famílias. Se em 1990 as chefes de família eram 20,3\%, esse percentual cresce para 22,5\% em 1995, para 26\% em 1999, ultrapassando, em 2004, os 30\% (LUCENA, 2010, p. 57). A PNAD 2010 revela que, em 2009, "um tipo de família considerado mais vulnerável - mulher sem cônjuge com filhos pequenos - é também composto, em maior proporção, por pessoa de referência de cor preta, 23,3\%, e parda, 25,9\%" (IBGE, 2011, p. 231). Nessa pesquisa, a proporção de mulheres brancas chegou a 17,7\%. Cabe assinalar que em 2004 a renda dos domicílios chefiados por mulheres, de acordo com o Departamento Intersindical de Estatística e Estudos Socioeconômicos (DIEESE), era inferior à das famílias chefiadas por homens.

Diante dos dados apresentados, não é ocasional que a exploração/opressão de gênero resulte no "predomínio das mulheres entre os(as) pobres e [que] o impacto das causas da pobreza [seja] carregado de significado de gênero, [...] [com] aumento tendencial da pobreza feminina no mundo contemporâneo" (LUCENA, 2010, p. 56), o que implica uma feminilização da pobreza, nos termos de Anderson (1994), segundo a referida autora.

Se a exploração/opressão étnico-racial e de gênero revelou-se, até o momento, extremamente nociva à vida dos(das) trabalhadores(as) em geral, ela se mostra bem mais danosa à parcela da classe trabalhadora negra, principalmente quando se observa o desemprego. No período de 1995 a 2006, verifica-se que, do total de desocupados no país, de acordo com Paixão e 


\section{temporalis}

Carvano (2008, p. 100), 60,4\% são pretos e pardos, dos quais 22,2\% são homens e 40,2\% mulheres. Na PEA branca, os desocupados equivalem a $38,3 \%$, sendo $9,8 \%$ de homens e $28,5 \%$ de mulheres. Os dados apresentados demonstram que, embora a flexibilidade seja um quadro geral, os(as) negros(as) continuam participando em grau diferenciado do desemprego e do emprego com maior grau de precariedade, portanto, em condição diferenciada do nível de exploração do trabalho pelo capital.

Dadas às transformações operadas no mundo do trabalho, é importante observar que, a partir da década de 1990, as relações de exploração/opressão de raça/etnia se aprofundam e se diversificam. Para Pochmann (2006, p. 65), a discriminação racial alcança novas formas de manifestação, principalmente quando se verifica que "a taxa de desemprego dos negros pobres cresceu menos", em decorrência de estarem vinculados aos trabalhos mais precários. Diferentemente do que ocorre com aqueles, o desemprego dos negros de média e alta renda explode. Esse fato, conforme o autor, deve-se ao "preconceito racial" que, "em um contexto de escassez de empregos especializados", atua "como um requisito decisivo na contratação". Logo,

a discriminação racial passou a excluir de ocupações mais nobres aqueles que, depois de muito esforço, haviam alcançado maior renda e escolaridade. No ambiente desfavorável do mercado de trabalho, o bloqueio à ascensão social tende a continuar crescendo no país, sobretudo para a população negra, mesmo quando esta alcança maior escolaridade (POCHMANN, 2006, p. 65).

Portanto, no contexto brasileiro, o racismo, ao mesmo tempo, deixou a grande parcela de trabalhadores(as) negros(as) no exército dos(das) desocupados(as) e distanciou-a do mercado formal de trabalho. Essa trajetória histórica, dentro da estrutura do capitalismo brasileiro, determinou a reprodução (social, econômica e política) dessa força de trabalho racialmente discriminada em condições extremamente diferenciadas, mesmo no âmbito da classe trabalhadora do país. 


\section{IMPLICAÇÕES POLÍTICO-SOCIAIS DO “LUGAR” DO(DA) NEGRO(A) NO MERCADO DE TRABALHO}

As análises desenvolvidas no item anterior possibilitam afirmar que as relações de exploração/opressão étnico/racial e de gênero, no âmbito do "capitalismo tardio", fizeram reproduzir e consolidar os empregos/ocupações dos(das) negros(as) nos setores onde a informalidade e a precariedade nas relações de trabalho são as marcas principais. Para Martins (2012, p. 211), são essas determinações que objetivamente impossibilitaram a parcela negra da classe trabalhadora de constituir politicamente a "questão social".

Nessa linha de discussão, Boschetti (2006, p. 84-87) afirma que a informalidade das relações de trabalho se constitui em "um dos elementos determinantes da não consolidação de uma 'condição salarial' no Brasil”. Por serem as relações salariais a referência a partir da qual "a intervenção estatal na questão social se organizou", a condição não assalariada apresenta determinações de peso. No Brasil, onde o trabalho assalariado "não se transformou em fator de integração nacional e onde as atividades precárias e informais proliferam, os direitos restritos às atividades salariais são [...] fonte de desigualdade, de exclusão social e de privilégios corporativos" (BOSCHETTI, 2006, p. 88). Nesse sentido, os não incluídos no mercado formal de trabalho, com carteira assinada, ficam à margem dos direitos sociais. Por serem, preponderantemente, os(as) trabalhadores(as) negros(as) os(as) não inseridos(as) em uma profissão regulamentada pelo Estado, a sua condição como trabalhador(a) se resume a uma condição de não cidadão(ã) em meio aos(as) cidadãos(ãs) inseridos(as) no processo produtivo formalizado e com o reconhecimento estatal, conforme os termos da definição de "cidadania regulada" de Santos (1987, p. 68).

Por estarem situados naquilo que Boschetti (2006, p. 90) chama de extremo das relações de trabalho - ou seja, "das relações [...] próximas da escravidão" e de garantias de "condições mínimas de sobrevivência material" -, os(as) racialmente discriminados(as) historicamente distanciaram-se do acesso a direitos mínimos, a exemplo de auxílio doença, aposentadoria e seguro desemprego. 


\section{temporalis}

As implicações político-sociais para a vida desses(as) trabalhadores(as) foram/são profundas. Diante das condições de trabalho acima referidas, os(as) negros(as) passaram a sofrer limitações nas possibilidades concretas de constituírem politicamente a "questão social". Uma vez "à margem da cidadania estratificada a partir das posições ocupadas no mercado de trabalho", esses(as) trabalhadores(as) desenvolveram o seu processo organizativo distante do espaço sindical e, como consequência, as suas demandas acabaram sendo "tratadas no âmbito do "exclusivo paternalismo" e/ou do "exclusivo 'caso de polícia"' (MARTINS, 2013, p. 14).

Ora, em meio a um regime de trabalho não universalizado para toda a classe trabalhadora e a um racismo encoberto pelo mito da "democracia racial", os(as) racialmente discriminados(as) foram mantidos(as) fora da "cidadania regulada". Por isso, aquela parcela de trabalhadores(as) domésticos(as) e autônomos(as), composta principalmente por negros(as), sofreu limitações para constituir politicamente a "questão social". A dispersão que caracterizava as suas ocupações diz muito da dificuldade de organização. Nesse contexto, os(as) negros(as) foram vistos(as) e tratados(as), pelo Estado, como um "não cidadão". Assim sendo, o assistencialismo e o braço armado do Estado se constituíram as respostas imediatas às expressões da "questão social" nas quais estavam inseridos(as).

Muito embora relutassem contra a dificuldade de organização - duplamente determinada pela cultura escravista e pela sua "exclusão" das relações de trabalho no segmento formal e regulado -, os(as) negros(as), por estarem inseridos(as) nas ocupações domésticas e/ou como trabalhadores(as) autônomos(as), acabaram colocados(as) naquelas condições de "fragmentação e dispersão". Essas condições, segundo Santos (1987, p. 31), "respondem pelo atraso, ou o descuido da ação protecionista governamental em relação a elas".

Reafirmando, em decorrência dessas condições, os(as) trabalhadores(as) negros(as) estiveram longe de constituir politicamente a "questão social". A sua condição de trabalhador não industrial trouxe limites para que as desigualdades étnico-raciais fossem explicitadas na arena política. No entanto, a sua resistência se deu no campo extrassindical, mesmo diante do 
quadro ideopolítico e do racismo impregnado na estrutura produtiva do capitalismo brasileira. Tal resistência deve ser inserida no âmbito da análise de lamamoto (2001, p. 28), ou seja, se a “"questão social' [é] desigualdade, [ela] também é rebeldia, por envolver sujeitos que vivenciam as desigualdades e a ela resistem e se opõem". Nesse sentido, a exploração/opressão étnico-racial e de gênero vai ser visibilizada por um Movimento Negro que, por várias décadas, construiu estratégias de luta contra as desigualdades a que estavam submetidos(as) os(as) negros(as) no país. Não é por acaso que os(as) negros(as) organizados(as) acumularam energia suficiente para pôr em questão a "democracia racial" e, no mesmo lastro, propor medidas na perspectiva de diminuir o abismo que separa os(as) discriminados(as) dos(das) não discriminados(as) racialmente no Brasil.

\section{CONCLUSÃO}

A análise das relações de exploração/opressão de raça/ etnia e de gênero torna-se importante, principalmente quando se busca apreender, nos processos sociais reais, as determinações que limitaram/impediram os(as) racialmente discriminados(as) de participarem da constituição política da "questão social". Evidentemente, não há como negar as determinações das relações étnico-raciais e de gênero na consolidação do "lugar" do(da) negro(a) na estrutura do capitalismo brasileiro.

Daí porque é fundamental que a análise das desigualdades na sociedade de classes considere, tanto do ponto de vista quantitativo como qualitativo, as condições de vida e de trabaIho dos(das) trabalhadores(as) racialmente discriminados(as). Ou melhor, busque entender por que os negros e, entre estes, as negras, são as mais pobres dentre os(as) pobres. Nessa perspectiva, uma análise dessa natureza nos leva a concordar com Lucena (2010, p. 60) em relação à necessidade de recorrer a Marx para entender "os dilemas societais e as grandes questões referentes ao ser [negro e] mulher [negra] em meio à barbárie do capital”. Por sinal, tal barbárie convida o "Serviço Social, [para] o desafio de articular, do ponto de vista teórico e profissional, a classe à raça/etnia e ao gênero na perspectiva de fortalecer a luta de classes pela superação da ordem do capital” (MARTINS, 2012, p. 212). 


\section{tempordils}

Sem dúvida, o desemprego e a precarização das relações de trabalho, como expressões da "questão social", devem ser analisados considerando as determinações das relações de exploração/ opressão de raça/etnia e de gênero. Nessa perspectiva, as mediações históricas, econômicas, políticas e culturais são fundamentais para apreender as determinações dessas relações nos processos sociais reais. O Serviço Social parece ser uma das profissões que têm maior possibilidade - por seu acúmulo teórico e prático - de tornar esse debate mais profícuo - principalmente se for encaminhado tomando a referência teórico-metodológica que garante a direção social do atual projeto ético-político profissional.

\section{REFERÊNCIAS}

ANDERSON, J. La Feminizacion de La Pobreza en América Latina. Lima: Red Entre Mujeres, 1994.

ANDREWS, G. R. Negros e Brancos em São Paulo (1888-1988). São Paulo: EDUSC, 1998.

BAIRROS, L. Mulher Negra: o reforço da subordinação. In: LOVELL, Peggy (Org.). Desigualdades Sociais no Brasil Contemporâneo. Belo Horizonte: UFMG/CEDEPLAR, 1991.

BALTAR, P. E.; PRONI, M. W. Sobre o Regime de Trabalho no Brasil: rotatividade da mão de obra, emprego formal e estrutura salarial. In: OLIVEIRA, C. A. B; MATTOSO, J. E. L. (Org.) Crise e Trabalho no Brasil: modernidade ou volta ao passado? São Paulo: Scritta, 1996.

BATISTA, M. A. R.; GALVÃO, O. M. R. Desigualdade racial no mercado de Trabalho brasileiro. Estudos Afro-Asiáticos, Rio de Janeiro, n. 23, dez. 1992.

BOSCHETTI, I. Seguridade social e Trabalho. Brasília: Letras Livres/ UNB, 2006.

BRUSCHINI, C; LOMBARDI, M. R. Mulheres e homens no mercado de trabalho brasileiro: um retrato dos anos 1990. In: MARUANI, M; 
HIRATA, H. (Org.). As novas fronteiras da desigualdade: homens e mulheres no mercado de trabalho. São Paulo: Senac, 2003. p. 323-356.

CANO, W. Desequilíbrios Regionais no Brasil: alguns pontos controversos. In: BELLUZZO, L. G. de M.; COUTINHO, R. (Org.). Desenvolvimento Capitalista no Brasil: ensaios sobre a crise. 4. ed. Campinas: UNICAMP; Instituto de Economia, 1998. v. 2.

FERNANDES, F. A Revolução Burguesa no Brasil: ensaio de interpretação sociológica. 5. ed. São Paulo: Globo, 2006.

HASENBALG, C. Discriminação e Desigualdades Raciais no Brasil. 2. ed. Belo Horizonte: UFMG; Rio de Janeiro: IUPERJ, 2005.

IAMAMOTO, M. V. O Serviço Social na Contemporaneidade: trabalho e formação profissional. São Paulo: Cortez, 2001.

INSTITUTO BRASILEIRO DE GEOGRAFIA E ESTATÍSTICA - IBGE. Indicadores Sociais Municipais: uma análise dos resultados do universo do censo demográfico 2010. Rio de Janeiro, 2011.

KERGOAT, D. Divisão sexual do trabalho e relações de sexo. In: MARLI, E. et al. (Org.). Trabalho e cidadania ativa para as mulheres. São Paulo: Coordenadoria Especial da Mulher, 2003.

KOWARICK, L. Trabalho e Vadiagem: a origem do trabalho livre no Brasil. 2. ed. Rio de Janeiro: Paz e Terra, 1994.

LESSA, S. Mundo dos Homens: trabalho e ser social. São Paulo: Boitempo, 2002.

LUCENA, M. F. G. Saúde, Gênero e Violência: um estudo comparativo Brasil/França sobre a saúde da mulher negra. Recife: Editora da UFPE, 2010.

LUKÁCS, G. Ontologia do Ser Social: os princípios ontológicos fundamentais em Marx. São Paulo: Ciências Humanas, 1979.

MANDEL, E. Introdução ao Marxismo. 4. ed. Porto Alegre: Movimento, 1982. 


\section{tempordils}

MARTINS, T. C. S. Racismo no mercado de trabalho: limites à participação dos trabalhadores negros na constituição da "questão social” no Brasil. Recife: UFPE. Tese de Doutorado, 2012.

. Racismo, questão social e serviço social: elementos para pensar a violação de direitos no Brasil. Revista Inscrital, Brasília, Ano 10, n. 14, p. 10-17, dez. 2013.

MARX, K. O Capital: crítica da economia política. Livro I. Tradução de Reginaldo Sant'Anna. 25. ed. Rio de Janeiro: Civilização Brasileira, 2008.

MATTOSO, J. E. A desordem do trabalho. São Paulo: Scritta, 1995.

MÉSZÁROS, I. Desemprego e Precarização: um grande desafio para a esquerda. In: ANTUNES, R (Org.). Riqueza e Miséria do Trabalho no Brasil. São Paulo: Boitempo, 2006.

NETTO, J. P. Cinco Notas a Propósito da “Questão Social”. Revista Temporalis, Brasília, ano 2, n. 3, p. 41-49, jan./jul. 2001.

PAIXÃO, M.; CARVANO, L. M. Relatório Anual das Desigualdades Raciais no Brasil; 2007 - 2008. Rio de Janeiro: Garamond, 2008.

POCHMANN, M. Desempregados do Brasil. In: ANTUNES, R. (Org.). Riqueza e Miséria do Trabalho no Brasil. São Paulo: Boitempo, 2006.

PORCARO, R. M. Desigualdade Racial e Segmentação do Mercado de Trabalho. Estudos Afro-Asiáticos, Rio de Janeiro, n. 15, jun. 1988.

SAFFIOTI, H. I. B. Gênero, patriarcado, violência. São Paulo: Perseu Abramo, 2004.

SANTOS, W. G. Cidadania e Justiça: a política na ordem brasileira. 2. ed. Rio de Janeiro: Campus, 1987. 